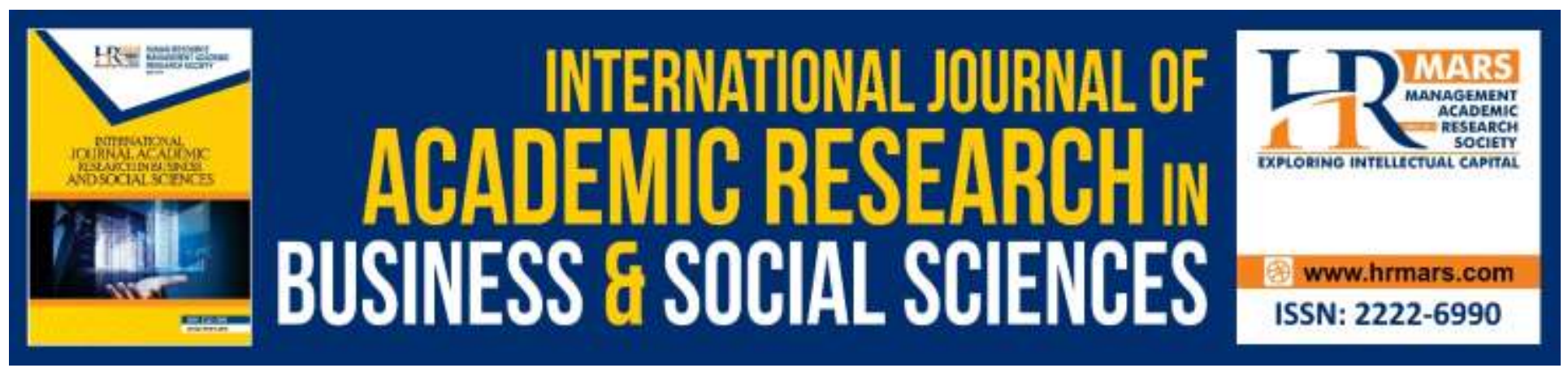

\title{
The Importance of Paternalistic Leadership Style and the Employee Wellbeing Among Air Traffic Controllers in Peninsular Malaysia
}

\section{Shafazawana Mohamed Tharikh and Siti Raba'ah Hamzah}

To Link this Article: http://dx.doi.org/10.6007/IJARBSS/v10-i5/7324

DOI:10.6007/IJARBSS/v10-i5/7324

Received: 16 March 2020, Revised: 20 April 2020, Accepted: 19 April 2020

Published Online: 27 May 2020

In-Text Citation: (Tharikh \& Hamzah, 2020)

To Cite this Article: Tharikh, S. M., \& Hamzah, S. R. (2020). The Importance of Paternalistic Leadership Style and The Employee Wellbeing Among Air Traffic Controllers in Peninsular Malaysia. International Journal of Academic Research in Business and Social Sciences, 10(5), 925-935.

Copyright: (C) 2020 The Author(s)

Published by Human Resource Management Academic Research Society (www.hrmars.com)

This article is published under the Creative Commons Attribution (CC BY 4.0) license. Anyone may reproduce, distribute, translate and create derivative works of this article (for both commercial and non-commercial purposes), subject to full attribution to the original publication and authors. The full terms of this license may be seen at: http://creativecommons.org/licences/by/4.0/legalcode

Vol. 10, No. 5, 2020, Pg. 925 - 935

http://hrmars.com/index.php/pages/detail/IJARBSS

JOURNAL HOMEPAGE

Full Terms \& Conditions of access and use can be found at http://hrmars.com/index.php/pages/detail/publication-ethics 


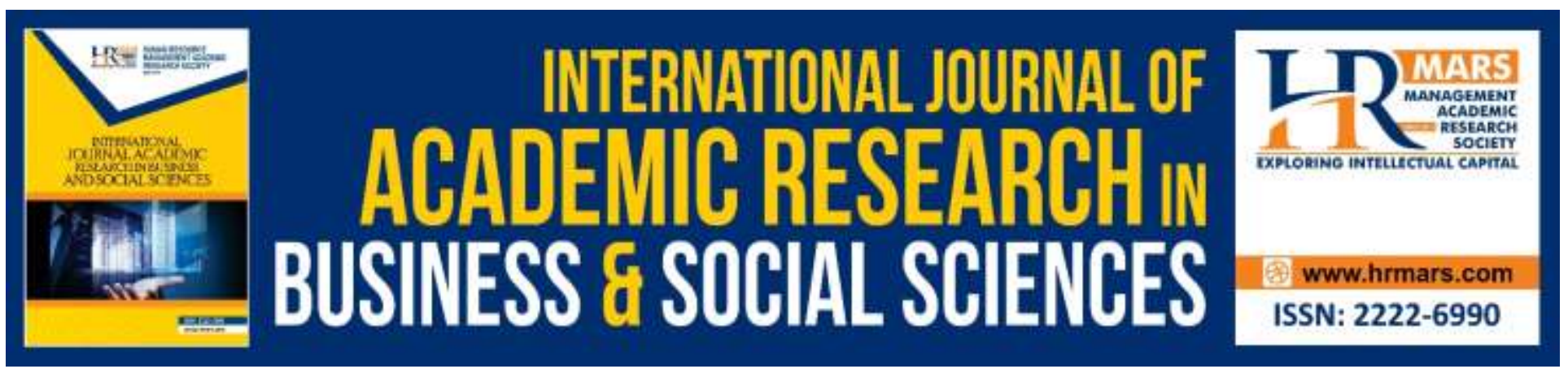

\title{
The Importance of Paternalistic Leadership Style and The Employee Wellbeing Among Air Traffic Controllers in Peninsular Malaysia
}

\author{
Shafazawana Mohamed Tharikh ${ }^{a^{*}}$ and Siti Raba'ah Hamzah ${ }^{b}$ \\ a College of Business Management and Accounting, University Tenaga Nasional, Malaysia, b \\ Faculty of Educational Studies, University Putra Malaysia, Malaysia \\ Email: shafa@uniten.edu.my
}

\begin{abstract}
Amongst many possible influential factors, leadership has been identified as an influential driver of employee wellbeing and innovative behavior. Many companies have replaced their traditional hierarchical management structures with empowered work teams to improve their efficiency and productivity. The relationship-oriented society in the well-known culture of collectivism in a country like Malaysia, where devotion, trust and a feeling of belonging is highly valued. Paternalistic leadership can be characterized as a caring leadership that consolidates resilient power of leaders with concern and kindness. Paternalistic leadership has offered a comprehensive understanding of leadership outside the western world. Despite the fact that the exploration of paternalistic leadership has thrived lately, the dissemination and character of paternalistic leadership has not been straightforwardly thought across eastern Asian nations. A quantitative approach with cross-sectional design as a survey method has been employed in this study and purposive sampling was used as the sampling technique. A total of 209 questionnaires were processed in this study. Partial Least Square-Structural Equation Modelling (PLS-SEM) was used to validate the research model and to test the hypotheses. Leadership styles have positive impact on employee wellbeing. Thus, this study has developed a new understanding of the impact of a leader's behavior based on paternalistic leadership styles on employee wellbeing among air traffic controllers (ATCs).
\end{abstract}

Keywords: Leadership, Paternalistic leadership style, Employee wellbeing, Air Traffic Controllers.

\section{Introduction}

Organizations have typically concentrated on diminishing pressure faced by employees instead of improving employee wellbeing (Hone et al., 2014). Level of employee wellbeing corresponds to the insight of personal differences, short-term effort and immoral leadership behavior which affect to a rising distrust in the workplace (Kozak et al., 2013; Baptiste, 2008). Supporting and encouraging wellbeing has the capability of profiting both the employees and the organization. The wellbeing of employees is essential for the survival and improvement of organizations worldwide (Spreitzer \& Porath, 2012; Wang \& Wang, 2016; Zheng et al, 2015). It has moreover been proposed 
that conceptualizations of workplace wellbeing ought to incorporate a segment of social connections, as this is a main part of an employee's encounter at work (Avey et al., 2010; Fisher, 2014; Robertson et al., 2010). The developing enthusiasm for workplace wellbeing has risen out of the general decline in the health of the workplace due to physical, psychosocial and individual factors (Ishak, Mahfar \& Yusof, 2016; Baptiste, 2008).

Management style is shown to be one of the four essential psychosocial work environment factors that are concerned with employee wellbeing at the workplace in the 21st century (Sparks et al., 2001). The researchers include leaders as the fundamental job players since they have a huge effect, positive or negative, on employee's lives since leaders are found to emphatically impact the job demand of employees, control and social support. In response to expanding the competition in the global economy, most of the companies have undergone dramatic structural changes. Among the few potential persuasive components, leadership has been distinguished as a compelling driver of employee wellbeing and inventive behavior (Choi, Tran \& Kang, 2017). Inceoglu et al. (2018) also Reb, Narayanan and Chaturvedi (2014) reported that the leadership literature, however, has largely neglected research on employee health, performance and wellbeing.

Many companies have replaced their traditional hierarchical management structures with empowered work teams to improve their efficiency and productivity. The relationship-oriented society in the well-known culture of collectivism in a country like Malaysia, where devotion, trust and a feeling of belonging is highly valued (Chan, 2014; Ibrahim \& Aida, 2012). Therefore, leaders must develop personalized relationships with their subordinates, particularly in work related factors (Ibrahim \& Mohd, 2014).

Air traffic controllers (ATCs) are working in shifts as they operate within a 24-hour schedule globally (Civil Aviation Authority of Malaysia (CAAM), 2018; Federal Aviation Administration (FAA), 2018). The shift schedules must be organized systematically by their supervisors and fair in terms of their shift lengths as well as their rest breaks to avoid ATCs' stress and fatigue which can affect to their wellbeing (Dall'Ora et al., 2016; Folkard, Robertson \& Spencer, 2007). Their job scope differs from other occupations (Falkland, Emma \& Wiggins, 2019) as they need to cope with advanced technology systems. Failure to deal with the advanced technology systems in the air traffic management settings (Öge, Cetin, \& Top, 2018) can cause three times higher cases of hypertension among ATCs compared to the normal age group (Cosic et al., 2019).

\section{Literature Review}

Wellbeing at work requires basic needs to be met and improved by conditions that include supportive personal relationships, community empowerment, healthy and alluring environment (Bakar et al., 2015). Enhancing performance or improving the execution by employees is not just an imperative issue for the organization yet also a solid explanation for an individual professional development and advancement (Zheng et al., 2015).

A good leader can contribute by demonstrating great consideration to the employees for their professional advancement, gives chances to gain from missteps, and show them how to perform better (Chan \& Mak, 2012). Human Resource Development (HRD) literature has focused on the fact that supervisors or leaders can induce terrible performance (Jing-Horng Lu \& Hsu, 2015; Zhang et al., 2015; Niu, Wang \& Cheng, 2009). Other studies by Mansor et al. (2012) and Wang et al. (2005) discovered that employee wellbeing is strongly influenced by the leadership styles (Mansor et al., 
2012; Wang et al., 2005). It is argued that positive leadership, must include passion, knowledge, skills, abilities and certainty to rouse followers, can possibly raise and elevate followers in the long term especially in trust, commitment, and wellbeing (Liu et al., 2010; Nanjundeswaras wamy, 2014).

Coined by Nanjundeswaras wamy (2014), a leader can be characterized as a person who delegates or affecting others to act on indicated objectives. The present organizations need effective and viable leaders who comprehend the complexities of the rapidly changing conditions worldwide. At the workplace, leaders' autonomy is distinct as independence in controlling over employees' methods of work, every employee initiative in planning their daily work activities and determining their own values in working performance also inspires employees to think autonomously when reacting to the difficulties and issues of work (Carlos et al., 2012; Einar et al.,2014; Ishak et al., 2016).

Despite the fact that exploration on paternalistic leadership has flourished of late, the scattering and character of paternalistic leadership has not been the direct idea crosswise over eastern Asian countries. It is believed that paternalistic leadership styles could contribute to organizations in Malaysia. One study on Malaysia conducted by Mansor et al. (2012) exhibit management styles namely autocratic, democratic, paternalistic and laissez faire. They found that paternalistic leadership style is the best style to predict employee wellbeing. Cheng et al. (2014) claimed that in their studies, sample from China, Japan, South Korea, and Taiwan disclosed the paternalistic leadership measurement model is fit for each of the four contexts countries .

In this sense, considering the importance of leadership style among ATCs, this study seeks to explain the gap on the relationship between paternalistic leadership style and employee wellbeing among ATCs based on the Malaysian context. Hence the following hypothesis is proposed:

\section{Hypothesis 1 (H1): Paternalistic leadership style significantly influence employee wellbeing.}

\section{Authoritarian}

Authoritarian leadership is characterized as the hierarchical dynamics between leaders' control, power, and authority (Aycan et al., 2013; Cheng et al., 2014). In any case, the theoretical dissimilarity is that autocratic leadership was developed in the western setting, while authoritarian leadership reflects the cultural characteristics (Zhang et al., 2015). Having a characteristically collectivist, feminine and high-power distance culture with high uncertainty avoidance (Öge, Çetin, \& Top, 2018) such as Malaysia which perceives that authoritarian leadership is an effective style and could contribute to positive outcomes.

In any case, in the opposite, Farh et al., (2004) expected that authoritarianism would advance workers' consistence and reliance. While Niu, Wang and Cheng (2009) believed that, those leaders who are practicing authoritarian leadership style would advance reliance and consistence by imposing strict discipline and high-performance standards on the employees while giving firm direction and guidelines to them. 
INTERNATIONAL JOURNAL OF ACADEMIC RESEARCH IN BUSINESS AND SOCIAL SCIENCES

Vol. 10 , No. 5, May, 2020, E-ISSN: $2222-6990$ ㄷ 2020 HRMARS

\section{Hypothesis 1a (H1a): Authoritarian significantly influence employee wellbeing.}

\section{Benevolence}

While subordinates comply with their supervisors, benevolence is conceded in return (Aycan et al., 2013; Cheng et al., 2014). Benevolent leaders put resources into their social relationship to the subordinate by giving individualized and all-encompassing concern if the subordinates experience individual and familial issues (Cheng et al., 2014; Farh et al., 2004). Benevolent leadership style is positively significant with the employee wellbeing among athletes (Jin-Horng \& Hsu, 2015).

While Chan and Mak (2012) conducted their study in China among non-profit organizations, and the benevolent leadership style is positively related to organizational performance. Benevolent leadership is positively related to enhance wellbeing (Erkutlu \& Chafra, 2016) and employee performance (Chen et al., 2014). Benevolence leaders are estimated to increase the employees' gratitude interchange (Farh et al., 2008). They are believed to improve reciprocity by helping employees when they face problems, personal emergency, provide welfare and empathy to employees and reward employees who deserve it (Niu, Wang \& Cheng, 2009).

\section{Hypothesis 1b (H1b): Benevolence significantly influence employee wellbeing. Moral}

The moral character element requires the leader to act as a role model to employees. Being an ethical good example is a significant function of paternalistic leadership in the Asian context (Cheng et al., 2014), henceforth, leaders are expected to behave on high moral standards and employee wellbeing. Various studies (e.g. Chan \& Mak, 2013; Cheng et al., 2014; Erkutlu \& Chafra, 2016) found that the moral characteristics of leaders contribute to positive wellbeing. Leaders are expected to behave on high moral characteristic standards, which empower subordinates to have faith in leaders' moral integrity and benevolence, and to follow their authoritarian guidance (Cheng et al., 2014).

\section{Hypothesis 1c (H1c): Moral leadership significantly influence employee wellbeing. Methodology}

Cross-sectional design and a quantitative approach has been employed in this study as a survey method while the sampling technique was purposive sampling.

\section{Respondents}

A total of 248 questionnaires were distributed to the targeted respondents in Region 1 Peninsular Malaysia, 209 questionnaires were returned with an 84.3 percent response rate. In this study, the highest number of respondents were male at 134 (64.1\%). Most of the respondents were at the ages ranged between 23 - 36 years. ATCs that are married was 178, which was $85.2 \%$ more than single ATCs. Malay ATCs were the highest in terms of ethnicity at both airports with $176(84.2 \%)$ of them, followed by 16 Indian (7.7\%), 10 Chinese (4.8\%) and 7 others (3.3\%). ATCs with 1-10 years of experience represented highest in number with 121 (57.9\%) respondents, while the least in number at $16(7.7 \%)$ ATCs were among those who had more than 30 years experience. 
INTERNATIONAL JOURNAL OF ACADEMIC RESEARCH IN BUSINESS AND SOCIAL SCIENCES

Vol. 10 , No. 5, May, 2020, E-ISSN: $2222-6990$ ㄷ 2020 HRMARS

\section{Questionnaires}

The procedure done in developing the survey instrument for this study consists of: (i) construct conceptualization, (ii) general items to represent the construct, (iii) assessment of the face and content validity of the items, (iv) scale evaluation and refinement and, (v) validation.

\section{Paternalistic Leadership Style}

Paternalistic leadership has been professed to be one prevailing leadership style in Asia (Cheng et al., 2014). Questionnaire for paternalistic leadership style which consisted of 12 -item was adapted from Paternalistic Leadership Scale by Cheng et al. (2014).

\section{Employee Wellbeing}

By reverberating the discoveries above in literature, and taking the orderly viewpoint, employee wellbeing in this study is consisted of subjective wellbeing, psychological wellbeing and workplace wellbeing. Flourishing scale with eight questions were adopted from Diener et al. (2009) which represented the psychological wellbeing while 12 questions with six items devoted to positive encounters and six items intended to assess negative experiences were adopted from Diener et al. (2009) which represented subjective wellbeing. Nine-items with four components; work satisfaction, respect from the employees, employer care and intrusion of workers' private life, represented workplace wellbeing was adapted from Hyett and Parker (2015).

\section{Data Analysis Validity}

Previous researchers suggest that the cut-off value for factor loadings should equal to and exceed 0.50 are acceptable, if the summation of loading results in high loading scores, contributing to AVE scores of greater than 0.5 (Byrne, 2013). Following these criteria, items with factor loading less than 0.50 were deleted. After removing two items which less than the recommended value, all measurement items range from 0.514 to 0.897 . Convergent validity is sufficient when variables have an AVE minimum value of 0.5 or more (Hair et al., 2013). All variables in the measurement model for this study are shown in Table 1 where AVE ranges from 0.501 to 0.759 , which exceeded the suggested threshold value of 0.5 . These results showed that the study's measurement model verifies an adequate convergent validity.

\section{Reliability}

When the composite reliability (CR) of every variable surpasses the edge value of 0.7 , the measurement model indicates an acceptable internal consistency reliability. CR of every variable for this study ranges from 0.914 to 0.966 as shown in Table 1 which is over the suggested threshold value of 0.7. It was concluded that the results demonstrated that the items used to represent the variables had satisfactory internal consistency reliability. 
INTERNATIONAL JOURNAL OF ACADEMIC RESEARCH IN BUSINESS AND SOCIAL SCIENCES

Vol. 10, No. 5, May, 2020, E-ISSN: 2222-6990 @ 2020 HRMARS

Table 1: Composite Reliability (CR) and Average Variance Extracted (AVE)

\begin{tabular}{lcc}
\hline & $\begin{array}{c}\text { Composite } \\
\text { Reliability (CR) }\end{array}$ & $\begin{array}{c}\text { Average Variance } \\
\text { Extracted (AVE) }\end{array}$ \\
\hline Authoritarian & 0.914 & 0.544 \\
Benevolent & 0.966 & 0.759 \\
Moral & 0.959 & 0.721 \\
Employee Wellbeing & 0.958 & 0.501 \\
\hline
\end{tabular}

Table 2 shows the result of measurement model's discriminant validity by utilizing Fornell and Larcker's (1981) measure. In light of the outcomes, all square roots of AVE exceeded the off-diagonal components in their related rows and columns. The bolded components in Table 2 represent the square roots of the AVE, and non-bolded values represent the inter-correlation value between variables. All off-diagonal components are lower than square roots of AVE (bolded on the diagonal). Subsequently, the outcome affirmed that the Fornell and Larker's measure was met. This study, therefore, presumes that the measurement model had set up its discriminant validity.

Table 2: Fornell and Larcker Criterion

\begin{tabular}{lrrrr}
\hline & Authoritarian & Benevolent & Moral & $\begin{array}{c}\text { Employee } \\
\text { Wellbeing }\end{array}$ \\
\hline Authoritarian & $\mathbf{0 . 7 3 8}$ & & & \\
Benevolent & 0.396 & $\mathbf{0 . 8 7 1}$ & & \\
Moral & 0.329 & 0.828 & $\mathbf{0 . 8 4 9}$ & \\
Employee Wellbeing & 0.300 & 0.448 & 0.495 & $\mathbf{0 . 6 8 6}$ \\
\hline
\end{tabular}

Table 3 shows that the first hypothesis $(\mathrm{H} 1 \mathrm{a})$ which was the relationship of authoritarian and employee wellbeing indicated that the relationship was statistically significant with t-value 2.928 with $\mathrm{p}$-value $<0.01$. The second hypothesis $(\mathrm{H} 1 \mathrm{~b})$ studied the relationship between benevolent and employee wellbeing which showed t-value 2.501 with $\mathrm{p}$-value $<0.01$. The next hypothesis $(\mathrm{H} 1 \mathrm{c})$ represented the relationship between moral and employee wellbeing and the result present the tvalue 3.343 with $p$-value $<0.01$. Based on output of the $t$-value, hypothesis 1 a to hypothesis $1 c$ were accepted. 
INTERNATIONAL JOURNAL OF ACADEMIC RESEARCH IN BUSINESS AND SOCIAL SCIENCES

Vol. 10, No. 5, May, 2020, E-ISSN: 2222-6990 @ 2020 HRMARS

Table 3: Result of Bootstrapping Analysis (Direct Effect)

\begin{tabular}{lcccc}
\hline \multicolumn{1}{c}{ Hypotheses } & Path & $\begin{array}{l}\text { Standard } \\
\text { Deviation }\end{array}$ & T Value & Decision \\
\hline $\begin{array}{l}\text { H1a: Authoritarian } \\
\text { Employee Wellbeing }\end{array}$ & 0.508 & 0.075 & $2.928^{* *}$ & Accepted \\
$\begin{array}{l}\text { H1b: Benevolent-> Employee } \\
\text { wellbeing }\end{array}$ & 0.450 & 0.134 & $2.501^{* *}$ & Accepted \\
$\begin{array}{l}\text { H1c: Moral-> Employee } \\
\text { wellbeing }\end{array}$ & 0.392 & 0.117 & $3.343^{* *}$ & Accepted \\
\hline
\end{tabular}

Note: $t$-value more than $1.64^{*}$ at $p<0.05$, t-value more than $2.33^{* *}$ at $p<0.01$

\section{Discussion of Findings}

Leadership and its outcomes are highly culture dependent (Choi, Tran \& Kang, 2017), Malaysian culture is more inclined to collectivism which is high in uncertainty avoidance and longterm culture dependency. Leadership style and practices plus behavior that will in general stifle and the emergence of dictators will infuse stress and strain among employees (Safaria et al., 2011). The exclusive component of this leadership style isthat business leaders received a paternalistic responsibility which combined both authoritarian, benevolent (Jing-Horng Lu \& Hsu, 2015) and moral practices. Authoritarianism, benevolent and moral leadership styles in this study were expected to integrate the levels into strong, cohesive group from the earliest vocation starting point in the organization. Leaders have an extremely distinguishable job in producing a solid organization, where employees can work to the maximum in an ideal manner.

\section{Conclusion}

This study may also indicate that the influence of disparity treatment at workplace can be counterbalanced by fair leadership. When the leaders and the management focus on attention to the needs of employees and showing willingness to handle them, it will foster the self-efficacy and wellbeing of employees (Öge, Cetin, \& Top, 2018).

By allowing ATCs to work more comfortably, the suggested improvements will increase positive wellbeing among ATCs. Key personnel such as the supervisors of ATCs, should postulate extensive guidelines to regulators for regulating indicators better and the workload of ATCs, as they are among the closest person that is well versed with the scenarios of their working styles. Managing workload should be good in practice to guarantee that employees' errands and duties can be practiced effectively within the time available. At the point when employees appreciate and feel associated with their work and where they feel aroused, they will carry out their responsibility well. Notwithstanding that, to bargain for air-traffic safety, the standard guidelines should be addressed and understood in the activity configuration process. This way, the expansion in the cognitive aspect of complexity and unpredictability in ATCs job could be identified with the requirement for them to modify the stereotypical activities of their designed tasks. 
INTERNATIONAL JOURNAL OF ACADEMIC RESEARCH IN BUSINESS AND SOCIAL SCIENCES

Vol. 10, No. 5, May, 2020, E-ISSN: 2222-6990 @ 2020 HRMARS

\section{Future Recommendations}

This study was focused only on civil ATCs in Malaysia due to its dominance in Air Traffic Management at CAAM. The other type of ATCs is the military which was excluded in this study because they have a different nature and focus. Hence, it is recommended that future studies should include this group to look at their specific context and problems with respect to leadership styles, or other factors such as ergonomics, and human resource management.

This study employed a quantitative research method aimed at reaching a statistical generation of direct relationship between paternalistic leadership style and employee wellbeing. However, some issues should be seriously taken into consideration, such as consistency in instrument development and validation. Due to this, some of the issues raised could be omitted by using qualitative study, so that they have ample time to witness the development of leadership style and employee wellbeing at selected workplaces.

\section{References}

Avey, J. B., Luthans, F., Smith, R. M., \& Palmer, N. F. (2010). Impact of positive psychological capital on employee well-being over time. Journal of occupational health psychology, 15(1), 17.

Aycan, Z., Schyns, B., Sun, J. M., Felfe, J., \& Saher, N. (2013). Convergence and divergence of paternalistic leadership: A cross-cultural investigation of prototypes. Journal of International Business Studies, 44(9), 962-969.

Bakar, A. A., Osman, M. M., Bachok, S., Ibrahim, M., \& Mohamed, M. Z. (2015). Modelling economic wellbeing and social wellbeing for sustainability: a theoretical concept. Procedia Environmental Sciences, 28, 286-296.

Byrne, B. M. (2013). Structural equation modeling with Mplus: Basic concepts, applications, and programming. Routledge.

Carlos M. P., Sousa, F. C., Guillamon-Saorin, E. (2012). Personal Values, Autonomy and Self-Efficacy: Evidence from Frontline Service Employees. International Journal of Selection dan Assessment, 20(2).

Chan, S. C. (2014). Paternalistic leadership and employee voice: Does information sharing matter? Human Relations, 67(6), 667-693.

Chan, S. C., \& Mak, W. M. (2012). Benevolent leadership and follower performance: The mediating role of leader-member exchange (LMX). Asia Pacific Journal of Management, 29(2), 285-301.

Cheng, B. S., Boer, D., Chou, L. F., Huang, M. P., Yoneyama, S., Shim, D., Sun, J. M., Lin, T. T., Chou, W. J., and Tsai, C. Y. (2014). Paternalistic leadership in four East Asian societies: Generalizability and cultural differences of the triad model. Journal of Cross-Cultural Psychology, 45(1), 82-90.

Cheng, M. Y., \& Wang, L. (2015). The mediating effect of ethical climate on the relationship between paternalistic leadership and team identification: A team-level analysis in the Chinese context. Journal of business ethics, 129(3), 639-654.

Choi, S. B., Tran, T. B. H., \& Kang, S. W. (2017). Inclusive leadership and employee well-being: the mediating role of person-job fit. Journal of Happiness Studies, 18(6), 1877-1901.

Civil Aviation Authority of Malaysia (CAAM) (2018). Retrieved from http://www.dca.gov.my/publications/ 
INTERNATIONAL JOURNAL OF ACADEMIC RESEARCH IN BUSINESS AND SOCIAL SCIENCES

Vol. 10, No. 5, May, 2020, E-ISSN: 2222-6990 @ 2020 HRMARS

Ćosić, K., Šarlija, M., Ivkovic, V., Zhang, Q., Strangman, G., \& Popović, S. (2019). Stress Resilience Assessment Based on Physiological Features in Selection of Air Traffic Controllers. IEEE access, 7, 41989-42005.

Dall'Ora, C., Ball, J., Recio-Saucedo, A., \& Griffiths, P. (2016). Characteristics of shift work and their impact on employee performance and wellbeing: A literature review. International journal of nursing studies, 57, 12-27.

Diener, E., Lucas, R. E., \& Scollon, C. N. (2009). Beyond the hedonic treadmill: Revising the adaptation theory of well-being. In The science of well-being (pp. 103-118). Springer, Dordrecht.

Einar, M. S., Sidselskaalvik, K. dan. (2014). Teacher Self-Efficay and Perceived Autonomy: Relations With Teacher Engagement, Job Satisfaction and Emotional Exhaustion. Psychological Reports: Employment Psychology \& Marketing, 114(1), 68-77.

Erkutlu, H., \& Chafra, J. (2016). Benevolent leadership and psychological well-being: The moderating effects of psychological safety and psychological contract breach. Leadership \& organization development journal, 37(3), 369-386.

Falkland, E. C., \& Wiggins, M. W. (2019). Cross-task cue utilisation and situational awareness in simulated air traffic control. Applied ergonomics, 74, 24-30.

Farh, L. J., Cheng, B., Chou, L. F., \& Chu, X. (2004). Authority and benevolence: Employee's responses to paternalistic leadership in China. Federal Aviation Administrations, 2018. Retrieved from https://www.faa.gov/

Fisher, C. D. (2014). Conceptualizing and measuring wellbeing at work. Wellbeing: A complete reference guide, 1-25.

Folkard, S., Robertson, K. A., Spencer, M. B. (2007). A Fatigue/Risk Index to assess work schedules. Somnologie 11 (3), 177-185.

Fornell, C., \& Larcker, D. F. (1981). Structural equation models with unobservable variables and measurement error: Algebra and statistics.

Hair, J. F., Hult, G. T. M., Ringle, C. M., \& Sarstedt, M. (2013). A Primer on Partial Least Squares Structural Equation Modeling (PLS-SEM). Thousand Oaks: Sage.

Hone, L. C., Jarden, A., Schofield, G. M., \& Duncan, S. (2014). Measuring flourishing: The impact of operational definitions on the prevalence of high levels of wellbeing. International Journal of Wellbeing, 4(1).

Hyett, M. P., \& Parker, G. B. (2015). Further examination of the properties of the workplace wellbeing questionnaire (WWQ). Social Indicators Research, 124(2), 683-692.

Ibrahim, R. Z. A. R., \& Aida, R. Z. (2012). Psychosocial work environment, organisational justice and work family conflict as predictors of Malaysian worker wellbeing (Doctoral dissertation, Victoria University).

Ibrahim, R. Z. A. R., \& Mohd, A. A. (2014). Malaysian Work Family Conflict wellbeing: the Moderating Role of Job Control and Social Support. Proc. of the Intl. Conf. on Advances in Social Science, Economics \& Human Behavior.

Inceoglu, I., Thomas, G., Chu, C., Plans, D., \& Gerbasi, A. (2018). Leadership behavior and employee well-being: An integrated review and a future research agenda. The Leadership Quarterly, 29(1), 179-202.

Ishak, A., Mahfar, M., \& Yusof, H. M. (2016). Sains Humanika A Review of Impact of Personality Big Five, Self-Efficacy and Autonomy on Job Satisfaction among Employees. 1(2013), 13-21. 
INTERNATIONAL JOURNAL OF ACADEMIC RESEARCH IN BUSINESS AND SOCIAL SCIENCES

Vol. 10, No. 5, May, 2020, E-ISSN: 2222-6990 @ 2020 HRMARS

Jing-Horng Lu, F., \& Hsu, Y. (2015). The Interaction between Paternalistic Leadership and Achievement Goals in Predicting Athletes'sportspersonship. Kinesiology: International journal of fundamental and applied kinesiology, 47(1), 115-122.

Kozak, A., Kersten, M., Schillmöller, Z., \& Nienhaus, A. (2013). Psychosocial work-related predictors and consequences of personal burnout among staff working with people with intellectual disabilities. Research in developmental disabilities, 34(1), 102-115.

Liu, J., Siu, O. L., \& Shi, K. (2010). Transformational leadership and employee well-being: The mediating role of trust in the leader and self-efficacy. Applied Psychology, 59(3), 454-479.

Mansor, N. N. A., Wai, C. M., Mohamed, A., \& Shah, I. M. (2012). The Relationship between Management Style and Employees' Well-Being: A Case of Non-Managerial Staffs. Procedia Social and Behavioral Sciences, 40, 521-529.

Nanjundeswaraswamy, T. S., \& Swamy, D. R. (2014). Leadership styles. Advances in management, 7(2), 57.

Niu, C. P., Wang, A. C., \& Cheng, B. S. (2009). Effectiveness of a moral and benevolent leader: Probing the interactions of the dimensions of paternalistic leadership. Asian Journal of Social Psychology, 12(1), 32-39.

Öge, E., Cetin, M., \& Top, S. (2018). The effects of paternalistic leadership on workplace loneliness, work family conflict and work engagement among air traffic controllers in Turkey. Journal of air transport management, 66, 25-35.

Reb, J., Narayanan, J., \& Chaturvedi, S. (2014). Leading mindfully: Two studies on the influence of supervisor trait mindfulness on employee well-being and performance. Mindfulness, 5(1), 3645.

Baptiste, R. N. (2008). Tightening the link between employee wellbeing at work and performance: A new dimension for HRM. Management Decision, 46(2), 284-309.

Robertson, I. T., \& Cooper, C. L. (2010). Full engagement: the integration of employee engagement and psychological well-being. Leadership \& Organization Development Journal, 31(4), 324336.

Safaria, T., bin Othman, A., \& Wahab, M. N. A. (2011). The Role of Leadership Practices on Job Stress among Malay Academic Staff: A Structural Equation Modeling Analysis. International Education Studies, 4(1), 90-100

Sparks, K., Faragher, B., \& Cooper, C. L. (2001). Well-being and occupational health in the 21st century workplace Kate. Journal of Occupational and Organizational Psychology, 74, 489-509.

Spreitzer, G., \& Porath, C. (2012). Creating sustainable performance. Harvard Business Review, 90(1), 92-99.

Wang, H., Law, K. S., Hackett, R. D., Wang, D., \& Chen, Z. X. (2005). Leader-member exchange as a mediator of the relationship between transformational leadership and followers' performance and organizational citizenship behavior. Academy of management Journal, 48(3), 420-432.

Wang, J., \& Wang, Y. (2016). The Impact of Character Strengths on Employee Well-Being: The Mediating Effect of Work-Family Relationship, 10(5), 1504-1512.

Zheng, X., Zhu, W., Zhao, H., \& Zhang, C. (2015). Employee well-being in organizations: Theoretical model, scale development, and cross-cultural validation. Journal of Organizational Behavior, 36(5), 621-644. 